\title{
Embryology of the Human Brain
}

\section{Kohei Shiota}

Congenital Anomaly Research Center and Department of Anatomy and Developmental Biology

Kyoto University Graduate School of Medicine, Kyoto, Japan

\begin{abstract}
In this paper, the process of CNS development in human embryos and fetuses is described. The primordium of the nervous system appears as early as during the third week after fertilization, but its differentiation and maturation require a considerably long period of time until after birth. Therefore, the developing brain is vulnerable to various kinds of deleterious environmental effects during the preand perinatal life. This paper aims at giving an overview of the major organogenesis of the brain in human embryos and fetuses.
\end{abstract}

Keywords Embryology of the human brain, neurulation in human embryos, myelination.

\section{EARLY INDUCTION OF THE NEURAL TISSUE}

The neural tissue, including the brain and spinal cord, arises from the ectodermal layer, which becomes identified in the embryonic disk during the second week after fertilization. The ectodermal tissue soon thickens to form the symmetrical neural plate, which is the forerunner of the brain and the spinal cord. By day 18 (Carnegie stage [CS] 8), a groove appears in the midline of the embryonic disk, which becomes deeper and longer due to the development of the bilateral neural folds along the lateral ends of the neural groove (Figs 1A, and B). By around day 20 (CS 9), the primordia of the three primary brain vesicles (the forebrain of prosencephalon, the midbrain or mesencephalon and the rhombencephalon) are discernible as thickenings in the neural plate. The bilateral neural folds begin to fuse with each other at about 22 days (CS 10) (Fig. 1C). This fusion initiates at the level of the future cervical region and extends to both cranial and caudal directions, to form a neural tube. The mode of fusion of neural folds is not the same in different species, and at least two initiation sites are recognized in human embryos (see the next section). The openings at the rostral and caudal ends of the neural tube, i.e. the anterior and posterior neuropores, close at 24 days (CS 11) and 28 days (CS 12), respectively, and complete the formation of the neural tube (Fig. 1D). If the closure of the neuropores are disturbed, various forms of neural tube defects (NTD) can occur.

Neural tube formation described above, which is accomplished by the fusion of neural folds, is called primary neurulation. On the other hand, the caudal end of the spinal cord is formed in a quite different fashion caudally to the posterior neuropore. This caudal part of the neural tube is induced in the mesenchyme (neural cord) of the tail bud or caudal eminence, and this developmental event is called secondary neurulation. Normal and abnormal secondary neurulation in human embryos is described in detail by Saitsu et al. ${ }^{1,2}$

\section{NEURULATION IN HUMAN EMBRYOS}

The closure of the human neural tube has conventionally been described as the process that begins in the region of the future neck (between the third and sixth somites) and proceeds both cranially and caudally like a zip fastener ("continuous closure model"). However, this continuous closure model of the human neural tube has recently been challenged. Based on the studies of NTDs in human clinical cases, van Allen et $\mathrm{al}^{3}$ proposed a "multisite closure model" where five initiation sites (four in the head and one in the lumbar region) are present during neural tube closure in human embryos. This intermittent or multisite closure model was derived from the observation of mouse embryos which have five closure sites in the neural tube ${ }^{4-6}$ but direct morphological evidence in human embryos at the neurulation stage was not provided.
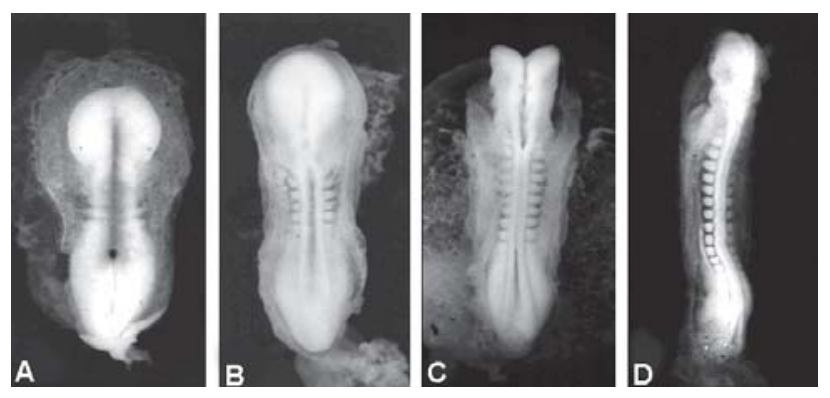

Figs 1A to D: Neurulation in human embryos: (A) 20 days after fertilization (Carnegie stage [CS] 9). Length $1.5 \mathrm{~mm}$. Neural plates and midline neural groove are recognizable. Somites are appearing. (B) 21 days after fertilization (early CS 10). Length $2.1 \mathrm{~mm}$. Seven pairs of somites. Neural folds are elevating and the neural tube is deeper. (C) 22 days after fertilization (late CS 10). Length $2.8 \mathrm{~mm}$. Ten pairs of somites. Neural folds are fusing to form the neural tube. (D) 24 days after fertilization (CS 11). Length $3.6 \mathrm{~mm}$. Fourteen pairs of somites. Neural tube closure is almost complete, leaving neuropores at the cranial and caudal ends (Congenital Anomaly Research Center, Kyoto University Graduate School of Medicine) 
In order to examine whether the closure of neural tube initiates at multiple sites in human embryos, we examined a substantial number of externally normal human embryos at the stages of neural tube closure (CS10 and 11) as well as those with cranial NTDs (CS11-23) in the Kyoto Collection of Human Embryos. ${ }^{7}$ Our gross and histological observation of human embryos with the closing neural tube indicated that human neural tube closure most likely initiates at multiple sites. In addition to the first closure (Site A) at the prospective cervical-trunk junction, the second initiation site of neural tube closure (Site B) was found around the mesencephalic-rhombencephalic boundary (Site B), which is only a 3 to 4 somite width cranial to "Site A" (Fig. 2). A careful review of the drawings of early human embryos in previous literature supports the finding that the second initiation site of neural tube closure occurs at the mesencephalic-rhombencephalic boundary. ${ }^{8-11}$ Since "Sites A and B" were observed simultaneously only in a few embryo cases with 10 somite pairs, it is likely that the opening between "Site A" and "Site B" closes rapidly during the later half of CS10, and therefore it is probably recognizable only for a few hours.

It should be noted that "Site B" initiates at the mesencephalic-rhombencephalic boundary but not at the prosencephalic-mesencephalic boundary as suggested by van Allen et al. ${ }^{3}$ In addition, no case was found in which two separate openings of the cranial NT were recognized over the prosencephalon and mesencephalon. We also found that the closure from Site A extends caudally to the end of the neural groove, where it completes the closure of the posterior neuropore. Further, it was found that the cranial extension of the closure from Site B meets the closure that started from the cranial end of the neural groove and extended posteriorly for a short distance. Based on these findings, we proposed a multisite closure model of the human neural tube (Fig. 3). It seems that the mode of NT closure in humans is not identical to that in rodents and other animal species, and therefore, we should be careful when extrapolating the embryological and teratological data obtained in laboratory animals to the human.

\section{GROSS PATTERN FORMATION OF THE BRAIN}

As described earlier, the three divisions of the embryonic brain (the prosencephalon, mesencephalon and rhombencephalon) can be recognized before neural tube closure begins. These three parts of the brain are called primary brain vesicles. Soon after the closure of the neural tube, it becomes bent by three flexures: (i) the mesencephalic flexure at the midbrain level; (ii) the cervical flexure at the junction between the rhombencephalon and the spinal cord, and (iii) the pontine flexure in the hindbrain (Fig. 4).

The forebrain soon divides into an end portion, the telencephalon and the diencephalon from which optic vesicles
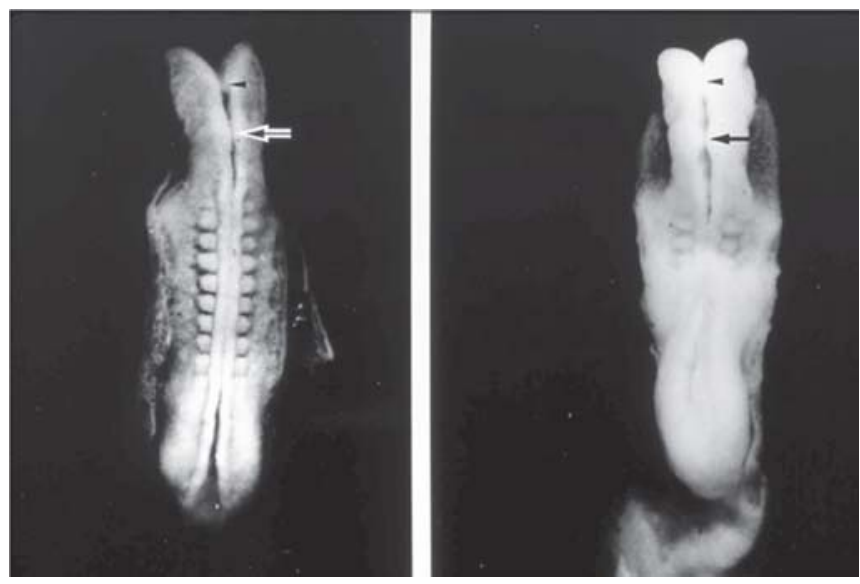

Fig. 2: NT is closing in the future cervical region in a 10-somite embryo at CS10. The bilateral neural folds are fusing at the future cervical region. Another initiation site of neural tube closure is observed at the level of the mesencephalic-rhombencephalic transition (arrow). The opposing medial walls of the mesencephalon appear to make contact with each other (arrowhead), but the neural tube closure does not initiate here (Nakatsu et al, 2000)

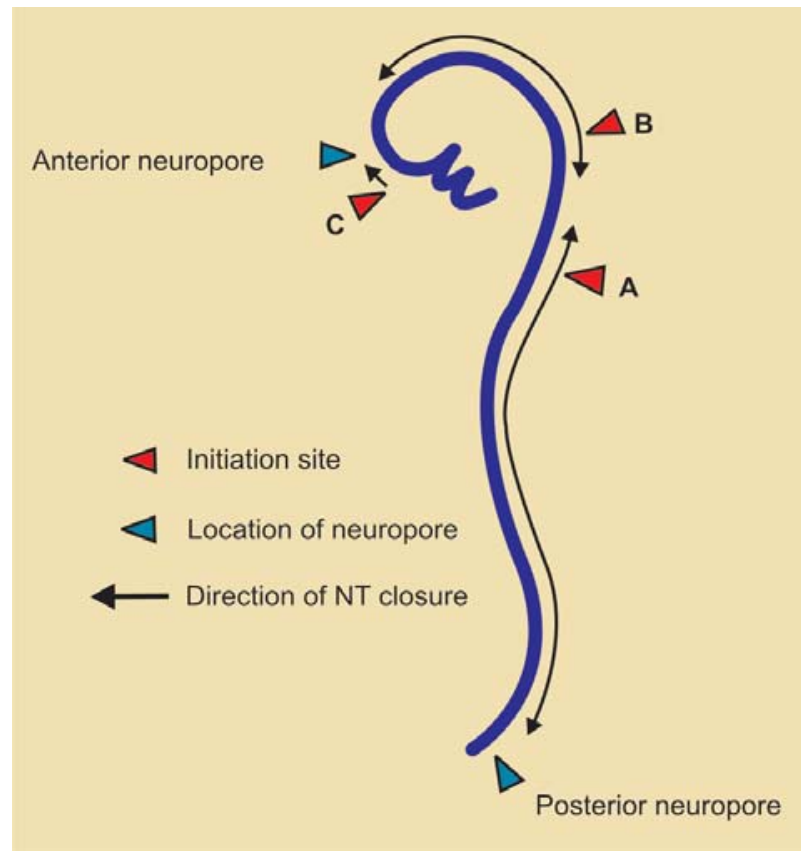

Fig. 3: Model for multisite closure of the neural tube in human embryos (Nakatsu et al. 2000). Red triangles indicate three initiation sites (A the cervical level, B the mesencephalic-rhombencephalic boundary, and $C$ is the rostral end of the neural groove) and arrows indicate the directions of the neural tube closure. The blue triangles show the sites of closure of the anterior and posterior neuropores

arise bilaterally. The hindbrain (rhombencephalon) also divides into a rostral part, the metencephalon, and a caudal part, the medulla oblongata. The junction between the midbrain and hindbrain is narrow and is known as the isthmus 


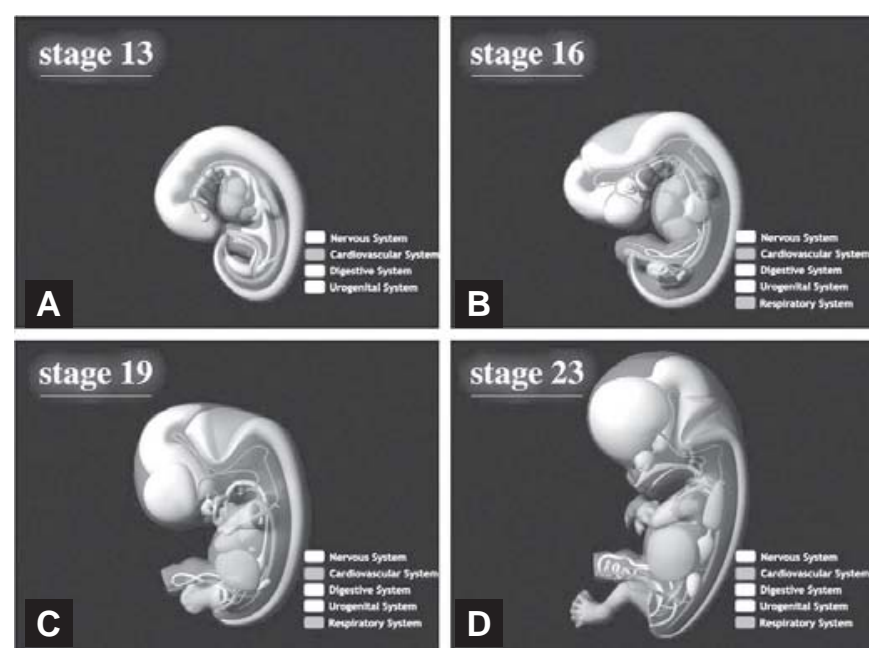

Fig. 4: Computer graphics models of human embryos showing major internal organs overlapped with the surface contour. The internal organs were reconstructed according to magnetic resonance images, histological sections, and textbook illustrations. A: CS 13. B: CS16. C: CS19. D: CS23 (Yamada et al, 2006)

rhombencephali. By CS15, the future cerebral hemischeres can be recognized in the trelencephalon. The cerebral hemispheres enlarge rapidly and completely cover the diencephalon by the end of the embryonic period.

During the feral period (nine weeks and later), the cerebral hemispheres continue to expand, due to the active formation and differentiation of neurons and glias (described in the next section), and form brain lobes, sulci and gyri (Figs 5A to D). In addition, the formation of commissural connections, the corpus callosum in particular, and the development of the cerebellum are important developmental events that occur during the feral period.

\section{HISTOGENESIS OF THE CEREBRAL CORTEX}

Up to 6 weeks of development, the neuroepithelium from which the brain and spinal cord arise appears as a homogeneous tissue comprising of neuroepithelial cells (Fig. 6). During the following weeks, some zones become recognizable histologically: (i) the ventricular zone, which is composed of ventricular cells and dividing neural precursor cells; (ii) the subventricular zone; (iii) the intermediate zone, through which neurous migrate radially along radial processes; (iv) the subplate; (v) the cortical plate, where postmitotic neurous condense and will become layers $\mathbf{I I - V I}$ of the mature cortex; and (vi) the marginal zone, the superficial layer important for establishing the laminar organization of the cortex (Figs 7A to D).

Cortical neurous are generated in the ventricular zone, migrate radially and reach their destination. The radial migration

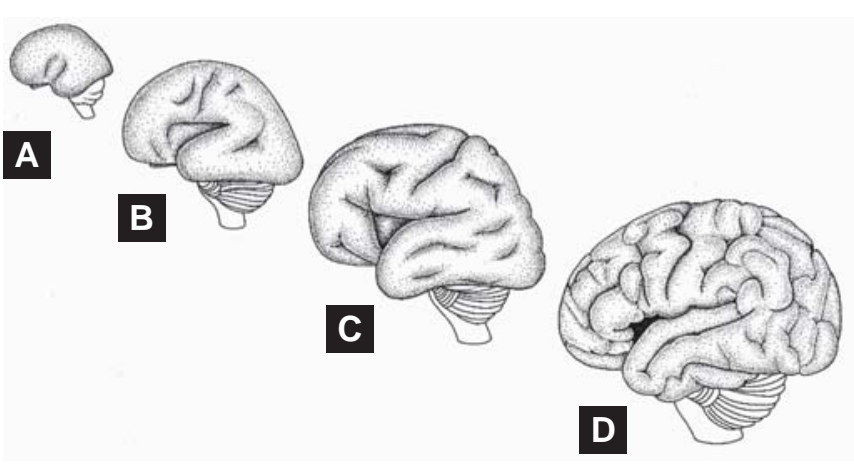

Figs $5 A$ to $D$ : Lateral views of the fetal brain in the fourth $(A)$, sixth (B) and eighth (C) months of gestation, and in a neonate (D) (Modified after ten Donkelaar et al, 2006)

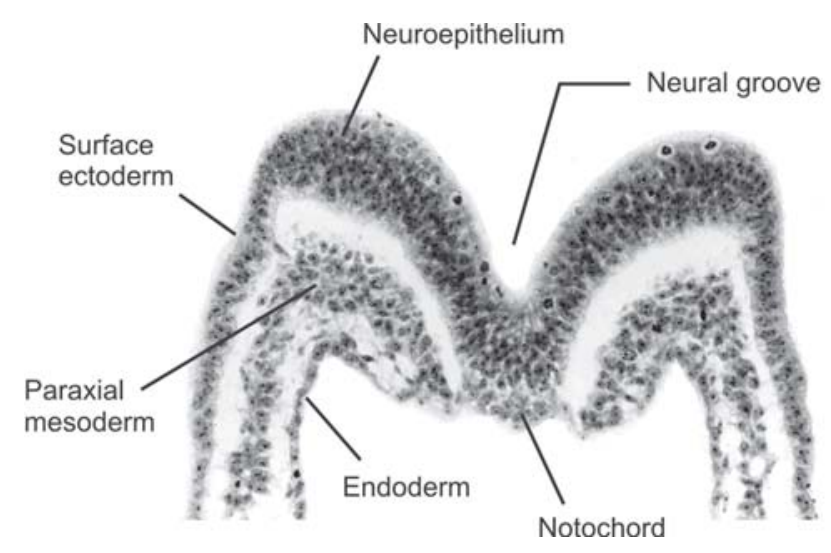

Fig. 6: A transverse section of a 21-day human embryo. Neuroepithelium and surface ectoderm are distinguishable from each other, and the neural groove is forming (Congenital Anomaly Research Center, Kyoto University Graduate School of Medicine)

is the mechanism by which developing neurous move along associated radial glial cells. The detailed description of the brain histogenesis is beyond the scope of this paper, and readers may refer to monographs by O'Rahilly and Müller ${ }^{12}$ and ten Donkelaar et $\mathrm{al}^{13}$ in which the development and developmental disorders of the human central nervous system are described comprehensively.

\section{MYELINATION}

For proper and effective function of the nervous system, the axons of fiber tracts need to undergo myelination. Myelination in the CNS is undertaken by oligodendrocytes, whereas that in the PNS depends on neurilemmal cells derived from the neural crest. The process is very slow, and the myelin begins to be present in the spinal cord at the end of the first trimester. ${ }^{14}$ In the brain stem, myelination starts at eight weeks of embryonic 


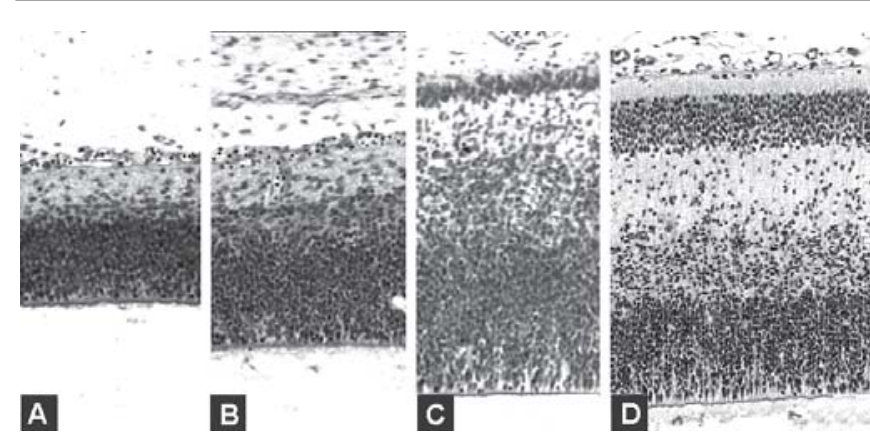

Figs 7A to D: Histological development of the human cerebral cortex: (A) 6 weeks; (B) 7 weeks; (C) 8 weeks; (D) 11 weeks

development. The vestibulospinal tract becomes myelinated at the end of the second trimester, and the pyramidal tracts begin later at the end of the third trimester. Myelination in these tracts completes after birth. The rate of myelin deposition is greatest during the first two years after birth, and cortical association fibers are the last to be myelinated (Fig. 8). Therefore, the human brain is rather immature at birth with regard to the degree of myelination.
Myelination results in a significant decrease in water content, which leads to a decrease in longitudinal relaxation times (T1) and transverse relation times (T2) on MRI. ${ }^{15,16}$ It has been shown that the appearance of myelin in MRI lags about one month behind the histological timetables. ${ }^{16,17}$

\section{MAGNETIC RESONANCE IMAGING (MRI) OF THE HUMAN EMBRYONIC BRAIN}

To observe and analyze the dynamic aspects of morphogenesis, it is essential to visualize the structures of embryos and their organs three-dimensionally. We applied imaging with a magnetic resonance (MR) microscope equipped with a 2.35 Tesla superconducting magnet to visualization of human embryo specimens and were successful to acquire high-resolution sectional images and identify the detailed structures of major organs including the brain. ${ }^{18}$

Figure 9 shows the 2D cross-sectional images of 4 fixed human embryos (CS22) selected from simultaneously acquired $3 \mathrm{D}$ datasets. The pulse sequence was a $\mathrm{T}_{1}$-weighted conventional 3D spin-echo sequence $(\mathrm{TR}=100 \mathrm{~ms}, \mathrm{TE}=8 \mathrm{~ms})$

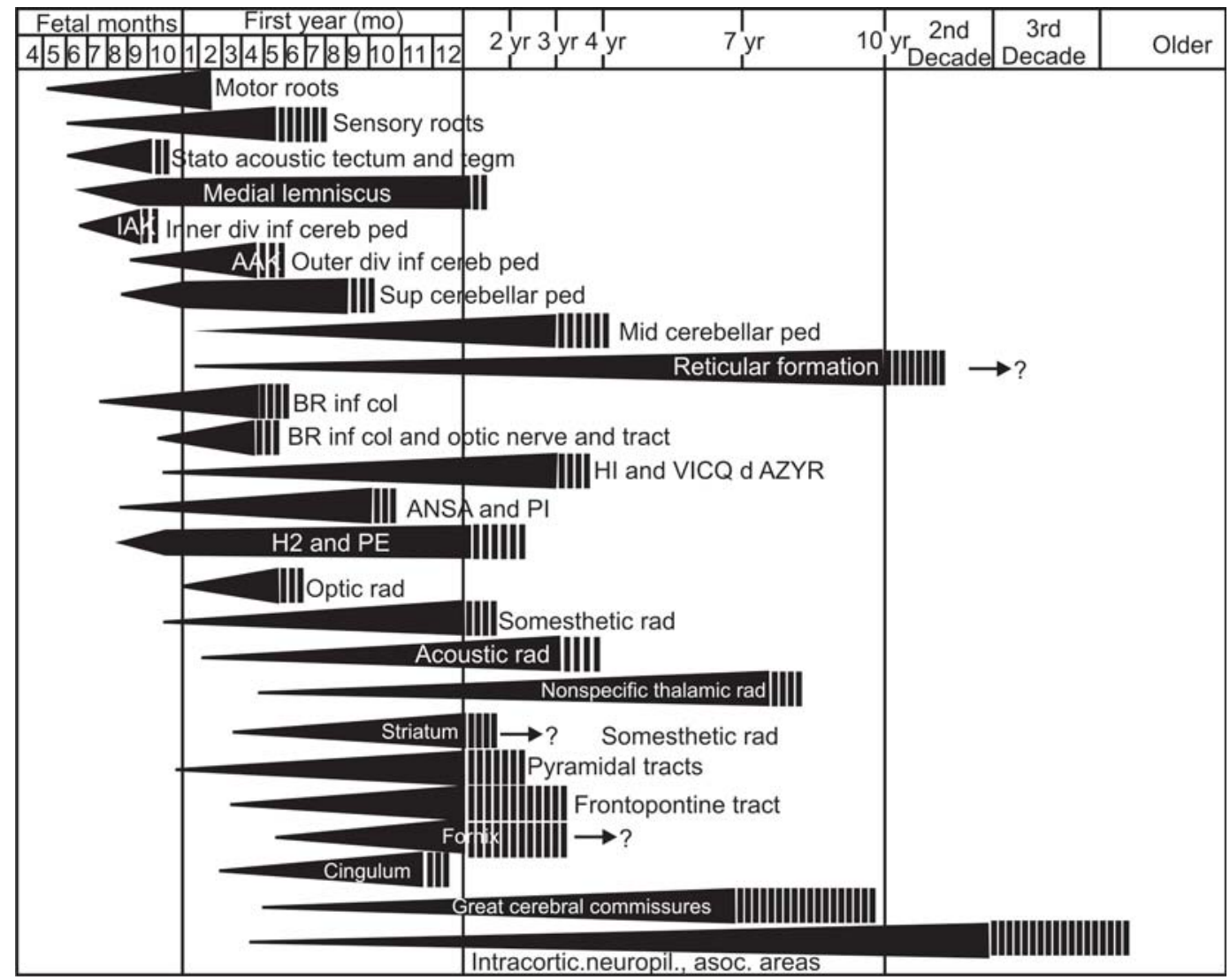

Fig. 8: Myelination of the main fiber tracts in the human central nervous system (Modified after Yakovlev and Lecours, 1967) 

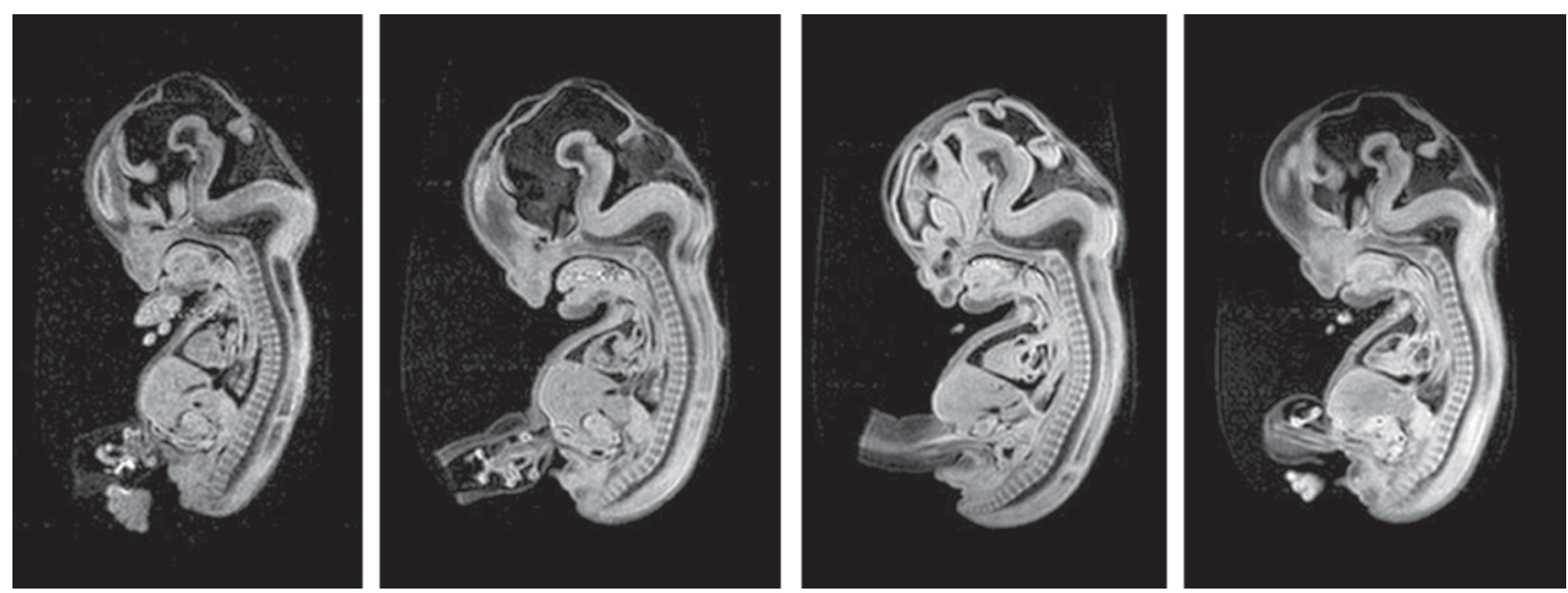

Fig. 9: Sectional images of four human embryo specimens (CS22) acquired simultaneously with the four-channel system of the super-parallel MR microscope. TR/TE $=100 \mathrm{~ms} / 8 \mathrm{~ms}$, spatial resolution $=(120 \mathrm{~mm}),{ }^{3}$ image matrix size $=128 \times 128 \times 256($ Shiota et al, 2007$)$

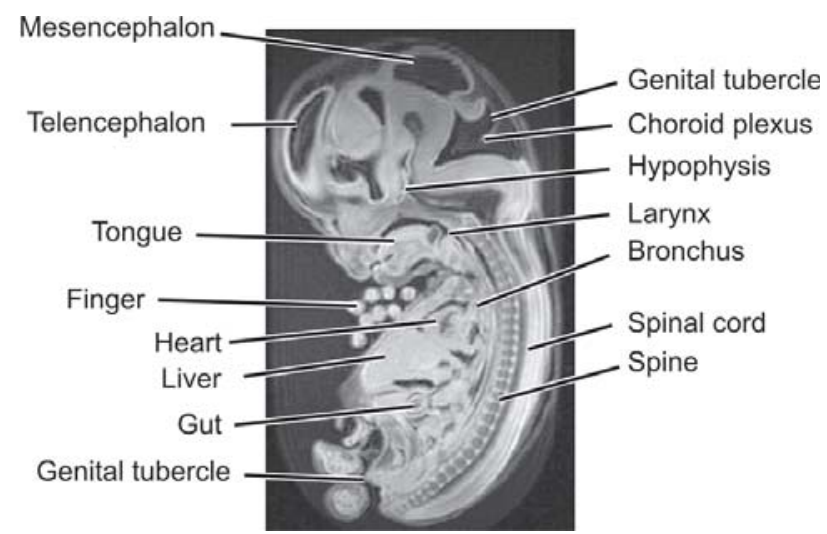

Fig. 10: MR image of a human embryo (CS23) in which the structures of major internal organs are identifiable (Shiota et al, 2007)

and the image matrix size was $128 \times 128 \times 256$. The resolution of these images is $120 \mathrm{~mm}^{3}$. The images had a similar SNR value and no interference was observed between the images acquired simultaneously.

Figure 10 shows that the MR image acquired as above enables identification of the structures in major organs of human embryos, as in detail as the images of low-magnification histological sections (X100 or lower magnifications). Thus it may be possible to identify by MR microscopy major structural abnormalities in the embryo, if there is any.

In Figure 11, 2D sectional images are shown for human embryos at CS18, CS20 and CS22. These sectional MR images again demonstrate the major anatomical structures in the embryo even in embryos smaller than $20 \mathrm{~mm}$ in length.

Using the sectional MR images, it is possible to generate the 3D images of each specimen. Figure 12 shows sectional MR images and 3D images of an embryo and its neural tube reconstructed using the amira ${ }^{\circledR}$ software (TGS Template Graphics Software, Inc., USA). The reconstructed images can be rotated on the viewing screen and cut at any desired planes to observe internal structures. Furthermore, the 3D images of developing human embryos can be generated and the sequential morphogenetic process can be demonstrated with the aid of computer graphics technique. ${ }^{19}$ 


\section{CS18}
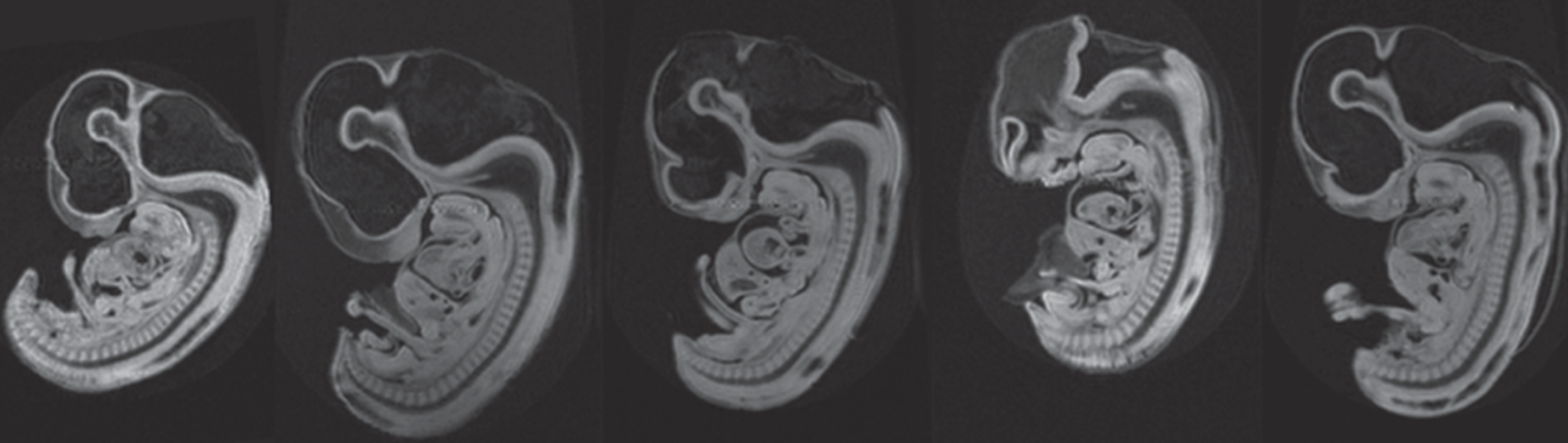

\section{CS20}
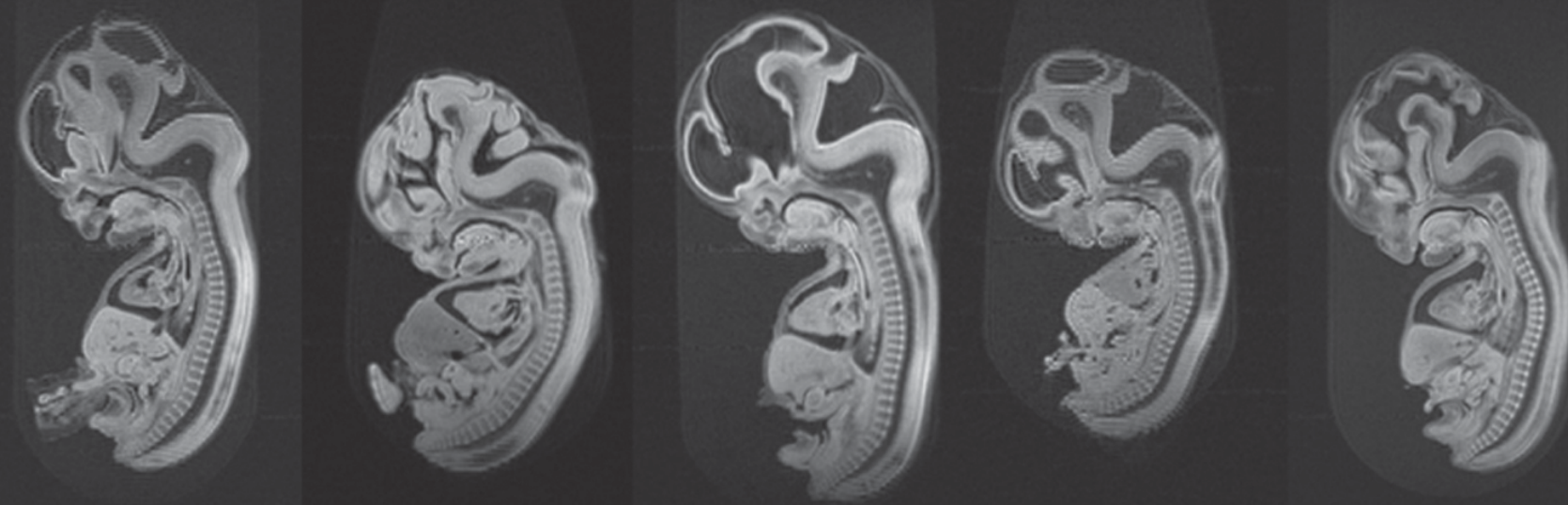

\section{CS22}
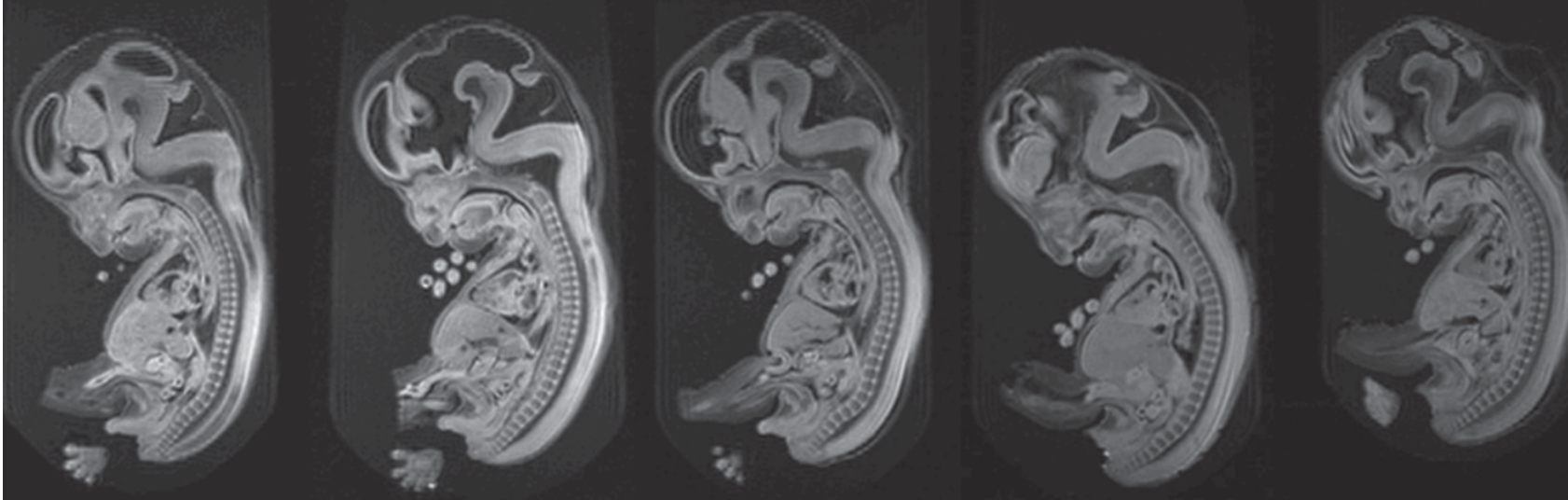

Fig. 11: 2D sectional images of human embryos at CS18, 20 and 22, selected from the datasets of staged human embryos (Shiota et al, 2007) 


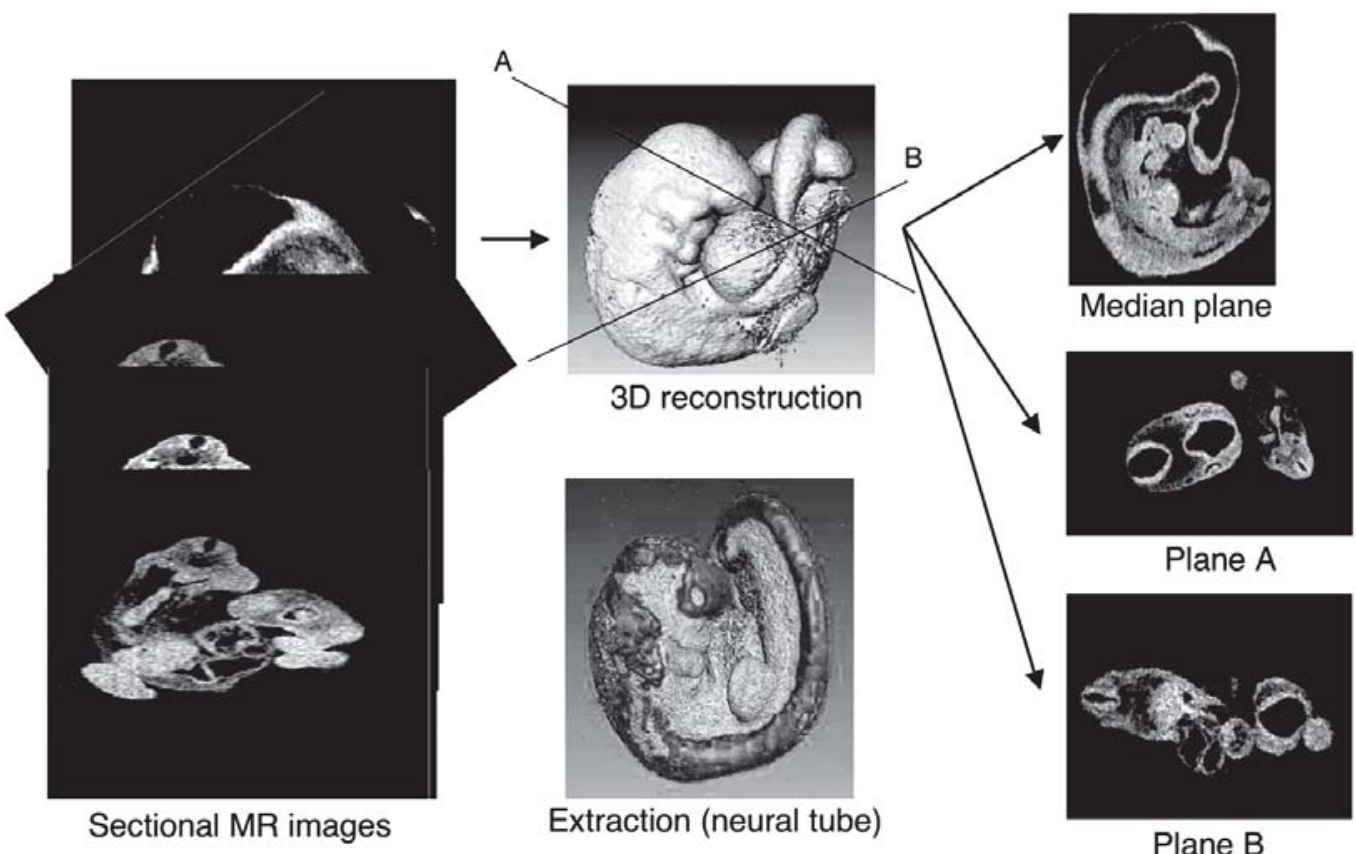

Fig. 12: 3D images of a human embryo and its neural tube (center) reconstructed from sectional MR data (amira $\left.{ }^{\circledR} 3.1\right)$ and its sectional MR images (left). Sectional images at desired planes can also be generated (right) (Shiota et al. 2007)

\section{REFERENCES}

1. Saitsu H, Yamada S, Uwabe C, Ishibashi M, Shiota K. Development of the posterior neural tube in human embryos. Anat Embryol 2004;209:107-17.

2. Saitsu H, Yamada S, Uwabe C, Ishibashi M, Shiota K. Aberrant differentiation of the axially-condensed tail bud mesencyme in human embryos with lumbosacral myeloschisis. Anat Rec 2007;290:251-58.

3. Van Allen MI, Kalousek DK, Chernoff GF, Juriloff D, Harris M, McGillivray BC, Yong SL, Langlois S, MacLeod PM, Chitayat D, Friedman JM, Wilson RD, McFadden D, Pantzer J, Ritchie S, Hall JG. Evidence for multi-site closure of the neural tube in humans. Am J Med Genet 1993;47:723-43.

4. Macdonald KB, Juriloff DM, Harris MJ. Developmental study of neural tube closure in a mouse stock with a high incidence of exencephaly. Teratology 1989;39:195-213.

5. Juriloff DM, Harris MJ, Tom C, MacDonald KB. Normal mouse strains differ in the site of initiation of closure of the cranial neural tube. Teratology 1991;44:225-33.

6. Golden JA, Chernoff GF. Intermittent pattern of neural tube closure in two strains of mice. Teratology 1993;47:73-80.

7. Nakatsu T, Uwabe C, Shiota K. Neural tube closure in humans initiates at multiple sites: evidence from human embryos and implications for the pathogenesis of neural tube defects. Anat Embryol (Berl) 2000;201:455-66.
8. Corner GW. A well-preserved human embryo of ten somites Contrib Embryol Carnegie Inst 1929;20:81-102.

9. Heuser CH, Corner GW. Developmental horizons in human embryos. Description of age group X, 4 to 12 somites. Contrib Embryol Carnegie Inst 1957;36:29-39.

10. Müller F, O'Rahilly R. The first appearance of the neural tube and optic primordium in the human embryo at stage 10. Anat Embryol (Berl) 1985;172:157-69.

11. Müller F, O'Rahilly R. The development of the human brain, the closure of the caudal neuropore, and the beginning of secondary neurulation at stage 12. Anat Embryol (Berl) 1987;176:413-30.

12. O'Rahilly and Müller. The Embryonic Human Brain: An Atlas of Developmental Stages (3rd ed). Wiley-Liss, New York, 2006.

13. ten Donkelaar H, Lammens M, Hori A (Eds). Clinical Neuroembryology. Springer, Berlin, Heidelberg and New York, 2006.

14. Yakovlev PI, Lecours AR. The myelogenetic cycles of regional maturation of the brain. In A Minkowski (Ed): Regional Development of the Brain in Early Life. Blackwell, Oxford, 1967;3-70.

15. van der Knaap MS, Valk J. MR imaging of the various stages of normal myelination during the first year of life. Neuroradiology 1990;31:459-70. 
16. van der Knaap MS, Valk J. Magnetic Resonance of Myelin, Myelination and Myelin Disorders (2nd ed), Springer, Berlin, Heidelberg and New York, 1995.

17. Ruggeiri PM. Metabolic and neurodegenerative disorders and disorders with abnormal myelination. In "Pediatric Neuroradiology" (WS Ball, Ed): Lippincott, Philadelphia 1997;175-37.

18. Shiota K, Yamada S, Nakatsu-Komatsu T, Uwabe C, Kose K, Matsuda Y, Haishi T, Mizuta S, Matsuda T. Visualization of human prenatal development by magnetic resonance imaging (MRI). Am J Med Genet (Part A) 2007;143A:3121-26.

19. Yamada S, Uwabe C, Nakatsu-Komatsu T, Minekura Y, Iwakura M, Motoki T, Nishimiya K, Iiyama M, Kakusho K, Minoh M, Mizuta S, Matsuda T, Matsuda Y, Haishi T, Kose K, Fujii S, Shiota K. Graphic and movie illustrations of human prenatal development and their application to embryological education based on the human embryo specimens in the Kyoto Collection. Dev Dyn 2006;235:468-77. 